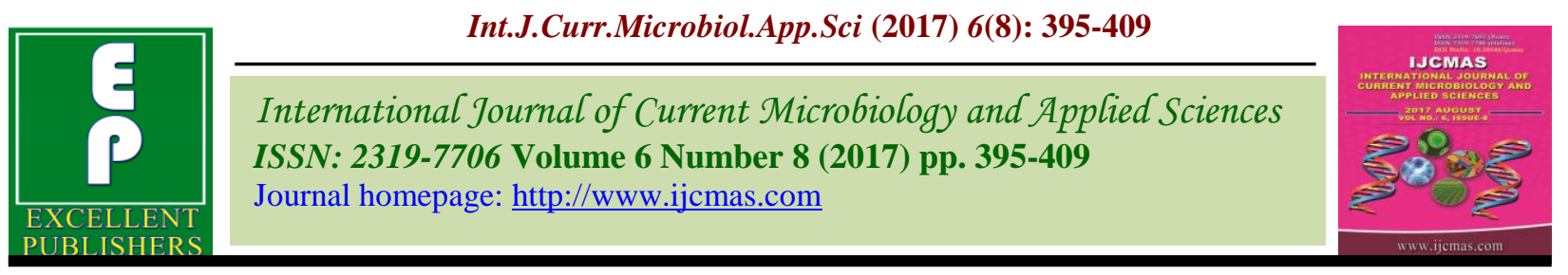

Original Research Article

https://doi.org/10.20546/ijcmas.2017.608.053

\title{
Comparative Study of Conventional Staining Techniques, Quantitative Buffy Coat, Immunochromatography Methods and Molecular Methods (Gene Amplification) for Diagnosis of Malaria
}

\author{
K.S. Vaisakhi ${ }^{*}$, Sujatha Kolla ${ }^{2}$ and Achut Rao ${ }^{2}$ \\ ${ }^{1}$ Dr. V. R. K. Medical College, STAR Hospitals, Hyderabad, Telangana, India \\ ${ }^{2}$ RVMIMS Medical College, Hyderabad, Telangana, India \\ *Corresponding author
}

\section{A B S T R A C T}

\begin{tabular}{|l|}
\hline K e y w o r d s \\
Microscopy, \\
Quantitative buffy \\
coat, Immuno- \\
chromatography, \\
PCR.
\end{tabular}

Keywords

Microscopy,

Quantitative buffy

coat, Immuno-

chromatography,

PCR

\section{Introduction}

Malaria is said to be the oldest disease in the world, as from Egypt, Indonesia, and China. Malaria means bad air. It is the one of the most important parasitic disease of humans affecting hundred and three endemic countries with a population over 2.5 billion people and causing between 1 and 3 million deaths every year worldwide. There has been a resurgence of the disease in many parts of the tropics.

In addition, there is continuing spread of drug resistant malaria especially of Plasmodium falciparum and Plasmodium vivax throughout South Asia, Western Pacific Central and South America. Due to this magnitude of drug resistance in India, the incidence of complicated forms of malaria increased. There is a compelling reason to justify the implementation of a rapid malaria diagnostic test in field. Diagnosis must therefore be immediate in order to provide proper treatment and prevent complications. Many rapid diagnostic methods have been introduced by the laboratories which would help in early diagnosis and thereby decrease the morbidity in endemic countries.

The $\mathrm{WHO}^{33,34,35}$ has initiated a project term as Role Back Malaria (RBM) to coordinate global actions. In view of the above criteria, 
the present study titled "Comparative Study of Conventional Staining Techniques, Quantitative Buffy Coat, immunochromatography Methods for Diagnosis of Malaria" was carried out in the Department of Microbiology at S. R. R. I. T. C. D. (Sir Ronald Ross Institute of Communicable Diseases), Nallakunta, under Osmania Medical College, Hyderabad.

Aims of the study are to compare the results of rapid diagnostic method with the conventional microscopy as it is the gold standard for diagnosis of malaria and to determine the sensitivity and specificity of various diagnostic methods and judge them and their usage in diagnosis and early treatment of the cases to prevent complications.

\section{Materials and Methods}

A total of 200 cases of fever were diagnosed by peripheral smear examination and blood samples were collected from patients attending S. R. R. I. T. C. D (Sir Ronald Ross Institute of Communicable Diseases), Nallakunta, under Osmania Medical College, Hyderabad.

\section{Smear}

Scratch free slides, lancet, Microscope, Cedar wood oil, Reagents for staining (Jaswant Singh Bhattacharjee (JSB), Leishman stain, Geimsa stain, Field's stain. The procedure is from Chaterjee K.D ${ }^{5}$, Cheesbrough ${ }^{7}$ with the techniques reference. Jaswant Singh Bhattacharjee (JSB): In-house the stain has been prepared following the preparation protocol.

\section{OptiMAL rapid malaria tests}

Immunochromatography is based on the capture of parasite antigen from peripheral blood using monoclonal antibodies prepared against malarial antigen target and conjugated to either liposome containing selenium dye or gold particle in a mobile phase. $2^{\text {nd }}$ and $3^{\text {rd }}$ capture monoclonal antibody applied to a strip of nitrocellulose acts as an immobile phase. The labelled antigen is to be captured by the monoclonal antibody of the immobile phase, producing coloured line.

The key enzyme regulating the energy metabolism of malarial parasite produce by sexual and asexual stages and is immunologically and structural different from host LDH. Only live parasites produce pLDH.

\section{Sample material}

Capillary blood collected by veni puncture.

Fresh blood collected by veni puncture.

Sample tubes containing anti-coagulant (EDTA) heparin.

\section{Kit contents: Dip sticks}

Conjugate wells

Wash well holder

Buffer

Lancets

Disinfectant wads

These should be store at $2-8^{\circ} \mathrm{C}$.

\section{Test procedure}

The kit should be allowed to reach the room temperature before use.

A dipstick from the container was taken and patients' identification was written on the label. (Hold always the dipstick by the label, do not touch the reaction field). 
One conjugate was placed and washed well in the holder.

One drop of buffer (approximately 20ml) was dispensed into the conjugate well and 4 drops (approximately $80 \mathrm{ml}$ ) into the wash well. Allowed to stand for 1 minute.

Aseptically the skin surface of the finger tip was cleaned with the disinfectant load, let to dry, the lateral part of the finger tip was pricked with the lancet. The load and the sterile lancet were discarded into a suitable waste container.

While gently squeezing the tube, the open end was immersed in the blood drop and then gently the pressure was released to draw blood into the pipette. When using whole blood, blood from the collection tube was drawn into the pipette.

One drop of blood (approximately 10 $\mu 1$ ) was added into the conjugate well. Mixed gently with the stirrer or the same pipette (upper end). Allowed to stand for 1minute, (the pipette was discarded into a suitable waste container). The approximate dipstick was placed vertically into the conjugate well and let it in the well for 10 minutes (the blood migrates towards the filter pad and the control band will appear progressively).

The dipstick was transferred from the wash well and the reactions were read.

The used dipstick was kept for future reference and post treatment monitoring.

\section{ParaHIT-f}

The malaria antigen test contains a membrane strip which is precoated with one monoclonal antibody as two separate lines across a test strip.

The monoclonal antibody (test line) is specific to the histidine rich protein of $P$. falciparum and another line which acts as control has goat anti-mouse antibody.

\section{Kit contains: Malaria antigen test kit}

Test strip.

Assay buffer.

\section{Specimen collection and storage}

Finger prick (venous blood) using lancet.

Whole blood into collection tube (Containing EDTA, citrate or heparin) by venipuncture.

Specimen not done immediately - refrigerated at 2-8 degrees Celsius, not more than 3 days, used within 3days.

\section{Test procedure}

Dispense $5 \mathrm{ml}$ of whole blood on the white sample pad allow blood to absorb into the sample pad for 60 seconds.

Dispense 300ul of assay buffer into a test tube.

Allow it to for 10 minutes.

Read the test strip after the blood colour has cleared 10 minutes.

Positive - presence of two colour bands indicates positive result for $P$. falciparum and control band.

Negative if no control band appears.

Invalid if only $P$. falciparum band appears.

\section{Polymerase Chain Reaction: Gene amplification}

PCR involves denaturation of DNA to from single DNA followed by annealing to allow binding of complementary strands of DNA 
fragments to 5 and 3 primers and finally primer extension catalysed by thermostable taq polymerase.

Each 1 parasite in $1 \mathrm{ml}$ can be detected with this test. Highly sensitive and specific, requires equipment and trained personnel.

Venous blood is collected with EDTA and stored at 4 degrees Celsius until test done.

Material: Extraction of DNA from infected RBC's

Infected erythrocytes

PBS (phosphate buffered saline).

$5 \%$ saponin solution.

Lysis buffer (40mu tris HCL, 80mu EDTA, $2 \% \mathrm{SDS}, 0.1 \mathrm{mg} / \mathrm{ml}$, proteinase $\mathrm{K}$ ).

The proteinase $\mathrm{K}$ was added just before using the buffer.

Phenol equilibrated with 0.1 uTris HCL.

Chloroform (removal of phenol).

RNase (RNase-it is a ribonuclease cock tail).

3u sodium acetate.

Absolute ethanol (helps in precipitation of DNA)

$70 \%$ ethanol (wash DNA (remove of salt)).

TE Buffer (10mu Tris-HCL; 1mu EDTA).

Primer from MGW company was taken. The primers for PCR procedure were chosen such that 5 primer was plasmodium conserved while the 3 primer were species specify.
Pf = A1 A1 (ATCAGCTTTTGATGTTAG GGTATT) A1 291 (GCTTATATTTGTATC TTTGAGC)

$\mathrm{Pv}=\mathrm{A} 1$ A1 (ATCAGCTTTTGATGTTAGG GTATT) A1 292 (TTCGCTTTTCATACTG $\mathrm{T})$

\section{Procedure}

Centrifuge the infected RBC at 3000xg for 2 minutes each cells once in cold PBS.

Resuspended cells from and microfuge tube (1. $7 \mathrm{ml})$ in $1 \mathrm{ml}$ of PBS.

10ul of $5 \%$ of saponin (for a final conc. 0 . $05 \%$ ) was added and gently mixed.

Immediately centrifuge at $6000 \mathrm{xg}$ for 5 minutes. The supernatant was removed to the $25 \mathrm{ul}$ of lysis buffer and $75 \mathrm{ul}$ of distilled water.

Incubated at 37 degrees Celsius for $\sim 3$ hours with intermittent stirring by hand.

100ul of distilled $\mathrm{H}_{2} \mathrm{O}$, then 200ul of phenol was added. Mixed well and centrifuged at $12,000 \mathrm{rpm}$ for 8 minutes.

Extracted with phenol and chloroform as above.

The genomic DNA was precipitated by adding 1/10 volume of sodium acetate and 2 . Five volume of absolute ethanol for a couple of hours or overnight at -20 degree Celsius. The DNA can be stored this way as well.

The precipitate was centrifuged for 30 minutes at 4 degrees Celsius, wash gently once with $70 \%$ ethanol, dry in speed-vac and gently resuspend the pellet in 25-100ul of distilled water, depending on its size. 
The DNA concentration was determined at OD 260, $2 \mathrm{ml}$ of culture may yield $\sim 2 \mathrm{ug}$ of genomic DNA runs as a high molecule weight, somewhat broad, band and is this unsheared and free of DNA.

PCR is set up with conditions.

Hot start - 95-1

Denaturation, Annealing, Extension, Further extenstion.

Agarose gel was set with $0.8 \%$.

4 gms of agar powder +1 x TAE (Tris Acetate EDTA) in $50 \mathrm{mi}$.

The mixture was placed in oven or heated for 2 minutes and set it in a tray with well stand and it will set in $1 / 2 \mathrm{hr}$. Take out well stand and the DNA ladder was loaded in the $1^{\text {st }}$ well and samples in other wells and the gel was run.

\section{Results and Discussion}

A total of 200 patients presenting with history of fever attending malaria clinic at Sir Ronald Ross Institute of Tropical and Communicable disease, Hyderabad were studied.

Among the patients there were 120 males, 80 females maximum number of cases were falling in the age group ranging from 16yrs to 60 yrs with mean age 24 to 48 yrs (Tables 2).

Blood samples were collected from 175 patients presenting with typical features regarding clinical malaria were subjected to various tests which included thin and thick smears stained with Jaswant Singh Bhattacharji, Giemsa, Leishman, Field's stain other methods employed for comparative study includes Acridine orange staining, Quantitative buffy coat method. Immunochromatography strips -OptiMAL and paraHIT -f assay are used. Gene amplification technique (Polymerase chain reaction) used (only 49 samples including I sample a negative control).

Of 200 samples taken from study who have been attending malaria clinic at S. R. R. I. T. C. D. 175 samples have been diagnosed clinically positive for malaria.

Demonstration of Malaria parasite in peripheral blood smears stained by JSB (Jaswant Singh Bhattacharjee) after thorough microscopic examination, was taken as the gold standard for definitive diagnosis of malaria

\section{Conventional technique}

Park ${ }^{24}$ of the 175 clinical positive cases $171(97.7 \%)$ of samples have been diagnosed by microscopy.

Out of which $92(53.8 \%)$ were found to be Plasmodium vivax 57(34. 7\%) were found to be Plasmodium falciparum and 15(8. 7\%) were mixed infection (both $\mathrm{Pv}$ and $\mathrm{Pf}$ were identified) the sensitivity $97.7 \%$ specificity $92 \%$ positive and negative predictive values are $98.8 \%$ and $85 \%$ respectively.

\section{Acridine orange staining}

Staining the blood smears with fluorescence dyes is a widely used procedure and has been recognised as a rapid and sensitive method. This technique has been found to be as sensitive as thick film preparation. This method is good for rapid screening.

Of $171(97.7 \%)$ positive smears, 97(56. 7) were found to be Plasmodium vivax and 74 (43. 2\%) were found to be Plasmodium falciparum. By this method it is difficult to segregate the mixed infection. The sensitivity aggregated the mixed infection. The 
sensitivity $97.7 \%$ and specificity $88 \%$ and positive and negative predictive values are $98.2 \%$ and $84.6 \%$ respectively.

Quantitative Buffy Coat fluorescing method is the more technically demanding and requires specialised equipment to separate the cell layers by centrifugation and good fluorescent microscopy. The results are as following:

Out of 175 clinically positive cases, 172 (93. $2 \%$ ) positive by QBC method, 90(54. 5\%) of which were found to be Plasmodium falciparum and 11(6. 4\%) were found to be mixed infection (both $\mathrm{Pv}$ and $\mathrm{Pf}$ ). The sensitivity was $98.2 \%$ and specificity $84 \%$ and positive, negative predictive values are $97.7 \%$ and $87.5 \%$ respectively.

\section{Immunochromatography assay}

\section{Histidine rich protein 2 detection kit}

It was the first antigen to be used to develop a rapid diagnostic test kit. The commercial kit used to detect this antigen is paraHIT $-\mathrm{f}$ (Span diagnostic Ltd).

Humar et al., ${ }^{10,}$ and Pieroni et al., investigated on ParaSIGHT $f$ test specificity and sensitivity.

Wongarichanalai et al., ${ }^{30}$, Shiff et al., Karbwang et al., assessed ICT and studied the sensitivity and specificity of HRP-2 Kit.

$74(93.6 \%)$ samples were found to be positive for Plasmodium falciparum. A total of 79 $(45.1 \%)$ smear were confirmed for mixed infection along Plasmodium falciparum. The sensitivity and specificity are $93.6 \%$ and $92 \%$ respectively. The positive predictive value is $97.3 \%$ and negative predictive value is $82 \%$.

\section{OptiMAL (Parasite lactate dehydrogenase detection kit)}

This test can be of clinical relevance. Different isomers of $\mathrm{pLDH}$ for each of four plasmodium species infecting humans exist and their detection constitutes a $2^{\text {nd }}$ approach for rapid diagnostic test (RDT) development. The commercially available kit optiMAL (Flow Inc. Portland oreg) was used in this study.

John et al., ${ }^{13}$ and Hunt-Cooke et al., ${ }^{11}$ confirmed the sensitivity and specificity of optiMAL.

Palmer et al., ${ }^{16,23}$, Fryauff et al., ${ }^{6}$, Mills et al., ${ }^{18}$, Jelinek et al., ${ }^{12}$, Tjitra et al., Eisen and Saul worked on the sensitivity and specificity of ICT test.

OptiMAL has showed $17.3(98.8 \%)$ positive cases of the clinically positive 175 cases. It could identify a few cases which could not be identified by microscopy due to low parasitemia. $75(43.3 \%)$ were Plasmodium vivax, $98 \quad(56.8 \%)$ were Plasmodium falciparum. Mixed infection could not be differentiated because the pan specific band consists of isomers of $\mathrm{pLDH}$ of all the four species. The sensitivity, specificity, positive, negative and predictive values are $98.8 \%$, $92 \%, 98.8 \%$ and $92 \%$ respectively.

Table.1 Field's stain contain 2 solutions

\begin{tabular}{|l|l|}
\hline Solution - A & Solution - B \\
\hline Methylene blue $-0.8 \mathrm{gms}$ & Eosin (yellow eosin) $-1 \mathrm{gm}$. \\
\hline Azure I (Azure B) $-0.5 \mathrm{gms}$ & Disodium hydrogen phosphate $-5 \mathrm{gms}$. \\
\hline Disodium hydrogen phosphate $-5 \mathrm{gms}$. & Potassium dihydrogen phosphate $-6.25 \mathrm{gms}$ \\
\hline $\begin{array}{l}\text { Potassium dihydrogen phosphate }-6 . \\
\text { 25gms. }\end{array}$ & Distilled water $500 \mathrm{ml}$. \\
\hline Distilled water 500ml & \\
\hline
\end{tabular}


Table.2 Total number of cases and gender variation

\begin{tabular}{|l|l|l|}
\hline Total cases & No. of Males & No. of Females \\
\hline 200 & 120 & 80 \\
\hline
\end{tabular}

Table.3 Smear examination with JSB

\begin{tabular}{|l|l|l|l|l|l|}
\hline Method & $\begin{array}{l}\text { No. of smear } \\
\text { examined }\end{array}$ & $\begin{array}{l}\text { Positive for } \\
\text { Plasmodium } \\
\text { vivax }\end{array}$ & $\begin{array}{l}\text { Positive for } \\
\text { Plasmodium } \\
\text { falciparum }\end{array}$ & Mixed infection & Total Positive \\
\hline JSB & 175 & $92(53.8 \%)$ & $64(37.4 \%)$ & $15(8.7 \%)$ & $171(97.7 \%)$ \\
\hline
\end{tabular}

Table.4 Smear examination with Acridine Orange

\begin{tabular}{|l|l|l|l|l|}
\hline Method & No. of smear examined & $\begin{array}{l}\text { Positive for } \\
\text { Plasmodium vivax }\end{array}$ & $\begin{array}{l}\text { Positive for } \\
\text { Plasmodium } \\
\text { falciparum }\end{array}$ & Total positive \\
\hline Acridine Orange & 175 & $97(56.7 \%)$ & $74(43.5 \%)$ & $171(97.7 \%)$ \\
\hline
\end{tabular}

Table.5 Smear examination with QBC

\begin{tabular}{|l|l|l|l|l|l|}
\hline Method & $\begin{array}{l}\text { No. of smear } \\
\text { examined }\end{array}$ & $\begin{array}{l}\text { Positive for } \\
\text { Plasmodium vivax }\end{array}$ & $\begin{array}{l}\text { Positive for } \\
\text { Plasmodium } \\
\text { falciparum }\end{array}$ & $\begin{array}{l}\text { Mixed } \\
\text { infection }\end{array}$ & Total positive \\
\hline QBC & 175 & $90(54.5 \%)$ & $71(41.2 \%)$ & $11(6.4 \%)$ & $172(98.2 \%)$ \\
\hline
\end{tabular}

Table.6 Smear examination with HRP-2

\begin{tabular}{|l|l|l|l|l|}
\hline Method & $\begin{array}{l}\text { No. of smear } \\
\text { examined }\end{array}$ & $\begin{array}{l}\text { Positive for } \\
\text { Plasmodium vivax }\end{array}$ & $\begin{array}{l}\text { Positive for } \\
\text { Plasmodium } \\
\text { falciparum }\end{array}$ & Total positive \\
\hline HRP-2 & 175 & - & $74(93.6 \%)$ & $79(49.1 \%)$ \\
\hline
\end{tabular}

Table.7 Smear examination with OptiMAL

\begin{tabular}{|l|l|l|l|l|}
\hline Method & $\begin{array}{l}\text { No. of smear } \\
\text { examined }\end{array}$ & $\begin{array}{l}\text { Positive for } \\
\text { Plasmodium vivax }\end{array}$ & $\begin{array}{l}\text { Positive for } \\
\text { Plasmodium } \\
\text { falciparum }\end{array}$ & $\begin{array}{l}\text { Total } \\
\text { positive }\end{array}$ \\
\hline OptiMAL & 175 & $75(43.3 \%)$ & $98(56.6 \%)$ & $173(98.8 \%)$ \\
\hline
\end{tabular}

Table.8 Smear examination with PCR

\begin{tabular}{|l|l|l|l|l|}
\hline Method & $\begin{array}{l}\text { No. of smear } \\
\text { examined }\end{array}$ & $\begin{array}{l}\text { Positive for } \\
\text { Plasmodium vivax }\end{array}$ & $\begin{array}{l}\text { Positive for Plasmodium } \\
\text { falciparum }\end{array}$ & Total positive \\
\hline PCR & 175 & $87.5(50 \%)$ & $86.5(49.42 \%)$ & $174(99.42 \%)$ \\
\hline
\end{tabular}

Table.9 Comparative study of different detection methods

\begin{tabular}{|l|l|l|l|l|}
\hline Method & Sensitivity & Specificity & Positive predictive & Negative predictive \\
\hline Microscopy & $97.7 \%$ & $92 \%$ & $98.8 \%$ & $85 \%$ \\
\hline Acridine orange & $97.7 \%$ & $88 \%$ & $98.2 \%$ & $84.6 \%$ \\
\hline QBC & $98.2 \%$ & $84 \%$ & $97.7 \%$ & $87.5 \%$ \\
\hline ParaHIT-f & $93.6 \%$ & $92 \%$ & $97.3 \%$ & $82 \%$ \\
\hline OptiMAL(pLDH) & $98.8 \%$ & $92 \%$ & $98.8 \%$ & $92 \%$ \\
\hline PCR & $98 \%$ & $100 \%$ & $99.9 \%$ & $96.1 \%$ \\
\hline
\end{tabular}


Table.10

\begin{tabular}{|l|l|l|l|l|}
\hline Studied by & Sensitivity & Specificity & Predictive positive & Values negative. \\
\hline Gay F $^{7}$ & $93.8 \%$ & $99.8 \%$ & $99.3 \%$ & $98.3 \%$ \\
\hline $\begin{array}{l}\text { David J. K Purnomo } \\
\text { et al.. }\end{array}$ & $99.6 \%$ & $81.7 \%$ & - & - \\
\hline Oloo et al. ${ }^{21}{ }^{32}$ & $98 \%$ & $84 \%$ & $97 \%$ & $98 \%$ \\
\hline Wang et al. ${ }^{2}$ & $87.2 \%$ & $95 \%$ & - & - \\
\hline Gaye O et al. ${ }^{8}$ & $100 \%$ & $83.6 \%$ & $93.4 \%$ & $100 \%$ \\
\hline Nandwani et al. ${ }^{20}$ & $97.5 \%$ & $100 \%$ & - & - \\
\hline Present study & $98.2 \%$ & $84 \%$ & $97.7 \%$ & $87.5 \%$ \\
\hline
\end{tabular}

Table.11

\begin{tabular}{|l|l|l|l|l|}
\hline Studied by & Sensitivity & Specificity & $\begin{array}{l}\text { Predictive } \\
\text { positive }\end{array}$ & $\begin{array}{l}\text { Values } \\
\text { negative. }\end{array}$ \\
\hline Tarimo DS et al. ${ }^{29}$ & $94.1 \%$ & $100 \%$ & $100 \%$ & $94 \%$ \\
\hline Present study & $97.7 \%$ & $88 \%$ & $98.2 \%$ & $84.6 \%$ \\
\hline
\end{tabular}

Table.12

\begin{tabular}{|l|l|l|l|l|}
\hline Studied by & Sensitivity & Specificity & $\begin{array}{l}\text { Predictive } \\
\text { positive }\end{array}$ & Values negative. \\
\hline Humar et al., ${ }^{10}$ & $100 \%$ & $98 \%$ & $95.4 \%$ & $100 \%$ \\
\hline N. Singh et al. ${ }^{28}$ & $93 \%$ & $92.5 \%$ & - & - \\
\hline Valecha N et al. ${ }^{27,28}$ & $98.5 \%$ & $97.1 \%$ & - & - \\
\hline Palmer CJ et al., ${ }^{16,23}$ & $94 \%$ & $88 \%$ & $88 \%$ & $99 \%$ \\
\hline Pinto MJW et al., ${ }^{25,26}$ & $100 \%$ & $84.5 \%$ & - & - \\
\hline Jelinck H et al., ${ }^{2}$ & $92.5 \%$ & $98.5 \%$ & - & - \\
\hline Wongchai S et al. ${ }^{30}$ & $97.2 \%$ & $96.3 \%$ & $77.8 \%$ & $99.6 \%$ \\
\hline Guthman JD et al., ${ }^{26}$ & $97 \%$ & $88 \%$ & - & - \\
\hline Pinto MJ et al. ${ }^{25,26}$ & $88 \%$ & $100 \%$ & - & - \\
\hline Present study & $93.6 \%$ & $92 \%$ & $97.3 \%$ & $8.2 \%$ \\
\hline
\end{tabular}

Table.13

\begin{tabular}{|l|l|l|l|l|}
\hline Studied by & Sensitivity & Specificity & $\begin{array}{l}\text { Predictive } \\
\text { positive }\end{array}$ & $\begin{array}{l}\text { Values } \\
\text { negative. }\end{array}$ \\
\hline C J Palmer et al., ${ }^{16,23}$ & $94 \%$ & $88 \%$ & $88 \%$ & $99 \%$ \\
\hline Mills CD et al., ${ }^{18}$ & $88-90 \%$ & $96-97 \%$ & - & - \\
\hline Jelinck H et al., ${ }^{12}$ & $88.5 \%$ & $99.4 \%$ & & \\
\hline Mason DD et al., ${ }^{17}$ & $86.2 \%$ & $76.9 \%$ & & \\
\hline Valecha N et al. ${ }^{27,28}$ & $61.8 \%$ & $100 \%$ & $100 \%$ & $71.8 \%$ \\
\hline C J Palmer et al., ${ }^{16,23}$ & $98 \%$ & $100 \%$ & $100 \%$ & $99 \%$ \\
\hline Present study & $98.8 \%$ & $92 \%$ & $98.8 \%$ & $92 \%$ \\
\hline
\end{tabular}

Table.14 Comparison of PCR studies for P. falciparum

\begin{tabular}{|l|l|l|l|l|}
\hline Studied by & Sensitivity & Specificity & $\begin{array}{l}\text { Predictive } \\
\text { positive }\end{array}$ & $\begin{array}{l}\text { Values } \\
\text { negative }\end{array}$ \\
\hline Gaye O et al., ${ }^{8}$ & $100 \%$ & $72.2 \%$ & $89.4 \%$ & $100 \%$ \\
\hline Trisophon W et al. ${ }^{31}$ & $92 \%$ & $100 \%$ & - & - \\
\hline S Nandwani et al. ${ }^{20}$ & $96.8 \%$ & $100 \%$ & - & - \\
\hline Present study & $98 \%$ & $100 \%$ & $99.9 \%$ & $96.1 \%$ \\
\hline
\end{tabular}


Int.J.Curr.Microbiol.App.Sci (2017) 6(8): 395-409
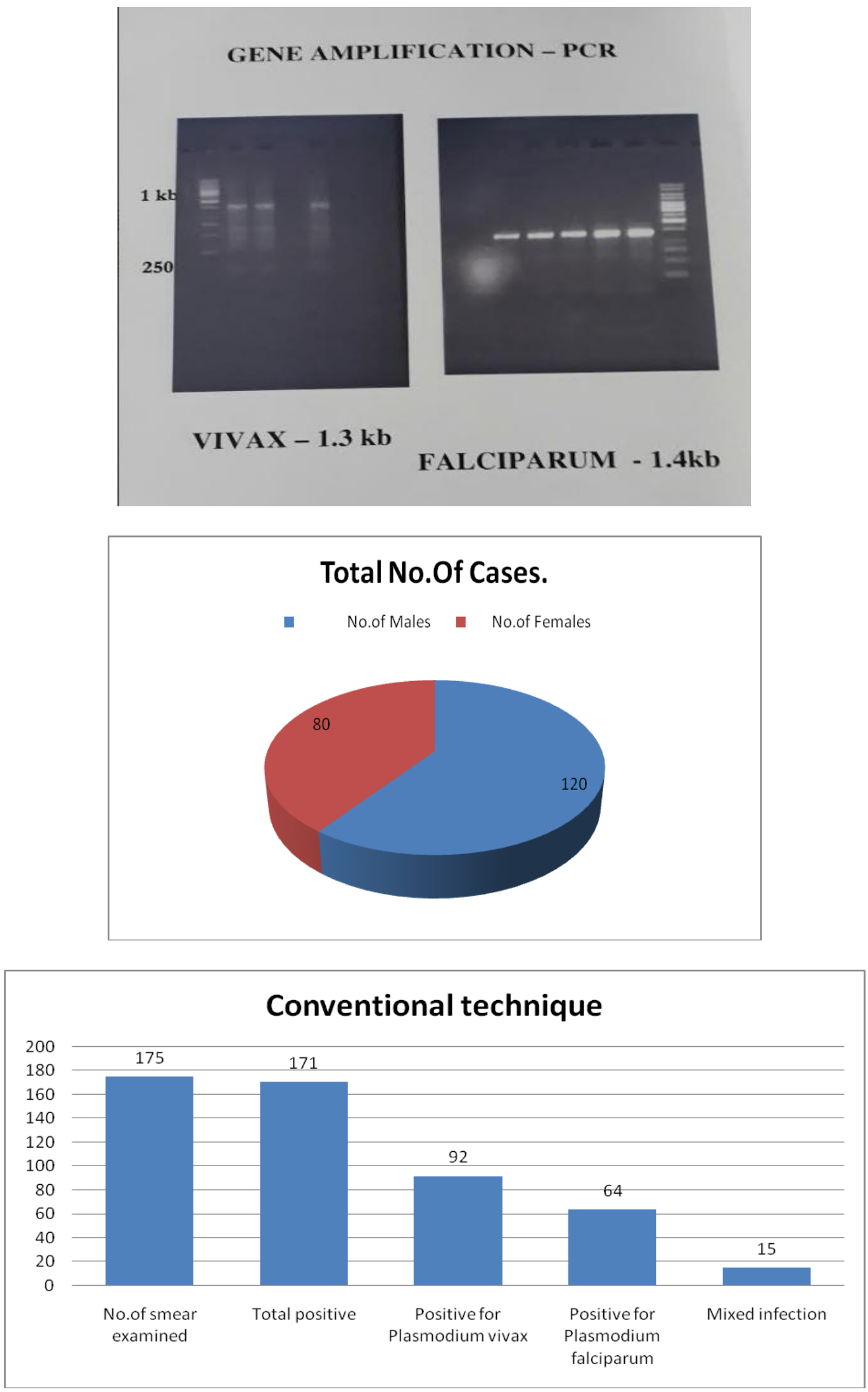

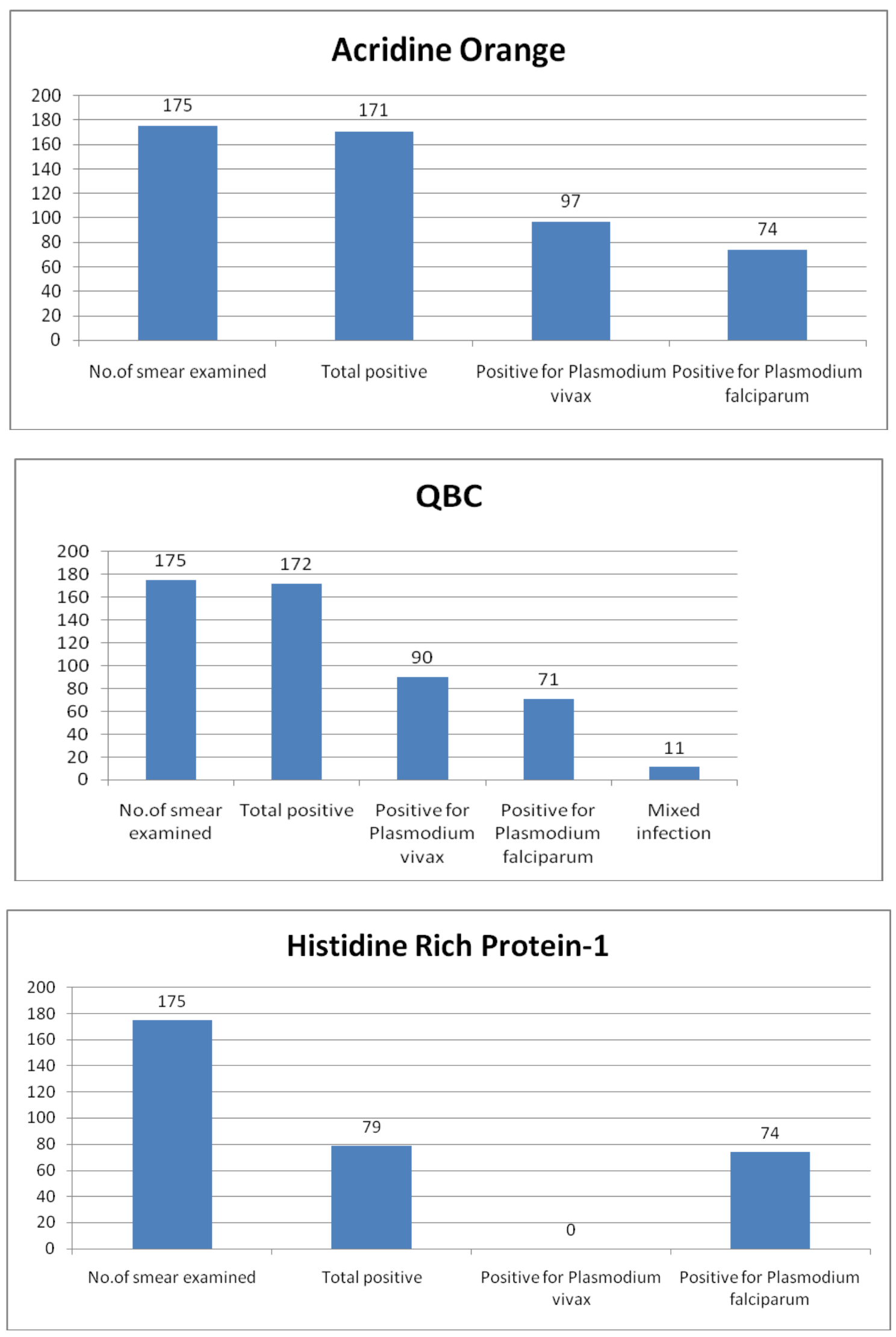

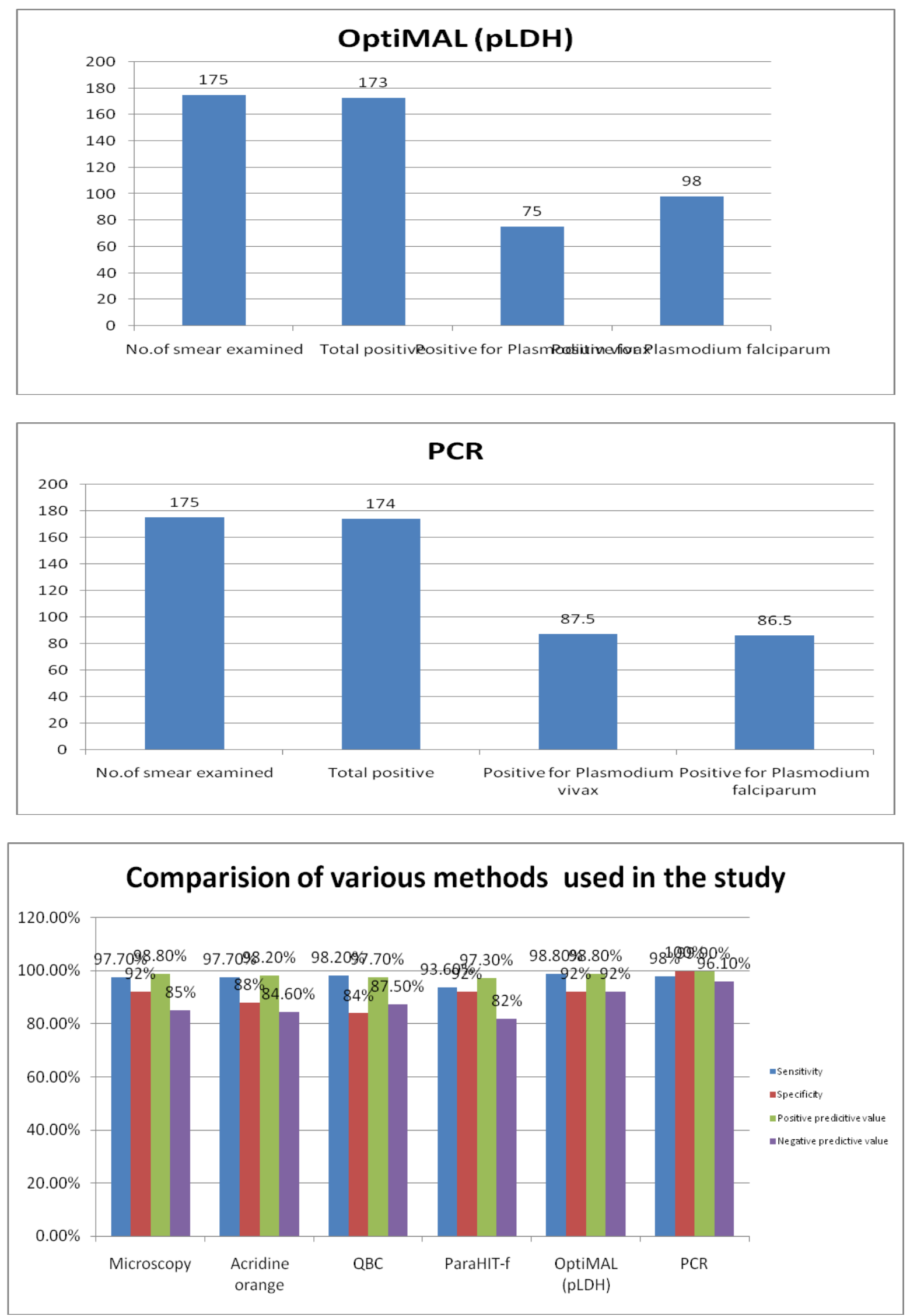


\section{Polymerase chain reaction}

In this study, 175 clinically positive cases samples which are smear positive were subjected to PCR analysis, one known negative control was included.

Srinivasan et al., ${ }^{19}$ studied that PCR detected DNA from blood of the patients who were suffering from malarial infection.

Quitana et al., studied the comparison of microscopy and PCR. Tagger and Jensen cultivate the parasite in vivo in the medium.

Of the 175 samples subjected to PCR analysis $87.5(50 \%)$ were Plasmodium vivax and 86. 5(49.4\%) were Plasmodium falciparum. The sensitivity was $98 \%$ specificity $100 \%$ and positive, negative predictive values are $99.9 \%$ and $96.1 \%$ respectively.

On comparison of the various methods used in the study, the following results have been observed.

Since the negative predictive value of a specific indicator of the efficacy test. It was found that pLDH optiMAL test showed the highest negative predictive value indicating that the test is most reliable in diagnosing this disease. The resurgence of malaria has renewed interest in developing not only preventive measures, but also rapid diagnostic techniques. Several methods have been developed to supplement and replace the conventional microscopic method of diagnosis. The most promising new malarial diagnostics are the immunochromatographic assays for detecting HRP -2 and $\mathrm{pLDH}$, Quantitative Buffy Coat, Acridine orange and Polymerase chain reaction. Microscopic examination of blood films is accepted as current universal gold standard for diagnosis of malaria.
The blood film is still the only widely available result against which the newer methods for diagnosis of malaria can be compared, even though microscopy continues to be method of primary choice for enumeration of parasites in blood film.

In this study the sensitivity, specificity, positive predictive value, negative predictive values of microscopy are $97.7 \%, 92 \%, 98$. $8 \%$, and $85 \%$ of which is taken us standard comparable findings.

All the results of the present study are compared with the conventional method.

Moody et al., ${ }^{19}$ studied about the possibility of replacing microscopy with ICT kits.

Comparison of quantitative buffy coat results

\section{Comparison of results of acridine orange staining}

In my study, both Quantitative Buffy Coat and in house prepared Acridine Orange staining were comparable and their sensitivity and specificity, positive negative predictive values were in concurrence.

The acridine orange staining technique was useful for rapid screening but speciation was difficult in few cases and mixed infections could not be differentiated. The limitation of the Acridine orange method is usage of fluorescent microscope or paralens with UV attachment.

Comparison of Histidine rich protein -2

The limitation of this method is as Histidine rich protein -2 is produced only by the Plasmodium falciparum only $\mathrm{P}$. $\mathrm{f}$ can be detected. 


\section{Comparison of parasite lactate dehydrogenase enzyme}

This test is more of clinical importance as this test detects $\mathrm{pLDH}$ from the live parasites only. The results of various studies mentioned above concurrence with results of present study. This kit could diagnose a few cases which are not detected due to low parasitemia by microscopy.

In this study only 175 cases have been studied, out of which 1 negative sample was taken as control. PCR has been claimed to the theoretically capable of detecting the presence of less than 5- 10 parasites in microlitre of blood. This technique is labour intensive and requires high level expertise and standardisation. PCR analysis was many time costlier, varying techniques used for extraction of DNA and source of printer. Hence PCR is now being used mostly for research purposes is very few centres.

Malaria being an endemic diseases in India and emerging disease in other countries in response, the WHO launched the Roll Back Malaria initiative, which has emphasized on early detection of malaria, in which kit methods have been given much importance and which comparable to conventional techniques.

Blood samples were collected from 175 patients presenting with typical features suggesting clinical malaria. The study showed that the immunochromatography assay tests were reliable and easy to use. Thus, this RDT is an appropriate test for the use in the field by paramedical staff when laboratory facilities are not available are thus likely to contribute greatly to an effective control of malaria in resource poor countries.

RDT's in conjunction with microscopy should improve diagnosis of malaria. However,
RDTS are more suited for investigator / health workers in situations where health services are different (or) absent.

In conclusion, this study investigated the use of non - microscopic, rapid optiMAL test is the best kit method. The performance of the test was adequate and the results obtained were correlated well with those obtained by microscopy.

The advantages of optiMAL test when compared with other methods are:

Availability of rapid results (10-15 mins).

Relative, simplicity compared with microscopy.

Can be used by relatively in experienced persons.

It is of clinical relevance.

Therefore, it is reasonable to consider future use of RDT's as an epidemiological too for the rapid screening of malaria. Where possible if microscopy and the RDT's can both be used together, the chance of missing the diagnosis of malaria will be remote. Hence it is suggested the RDT's also may be supplied to malaria clinics and their use is encouraged.

Molecular techniques are sensitive, accurate and specific but expensive and require expert knowledge hence their practical application is restricted in our country.

\section{References}

1. Chatterjee K. D. Text book of parasitology $1987,12^{\text {th }}$ edition $71-100$.

2. Cheesebrough; District laboratory practices in tropical countries 239-258. 
3. Craig MH, Sharp B. L., Comparative evaluation of four techniques for the diagnosis of $P$. falciparum infections. Tran R Soc. Trop. Med. Hyg. 1997; 91: 279-82.

4. David J. K. Purnomo and T. R. Jones, 1992 Diagnosis of malaria in the field by fluorescence microscopy of QBC, Capillary tubes. Trans. R. Soc. Trop. Med. Hyg., 86: 35.

5. Cooke A. H., et al., 1992 use of the flouruchrome benzothiocarboxypurine in malaria diagnosis is an endemic area. Trans. R Soc. Trop. Med. Hyg., 87: 549.

6. Fryauff D. Et al., 2000. Performance of optimal assay for detection and identification of malaria infection is asymptomatic resident of Irian. Ann. J. Trop. med. Hyg. 03: $139-145$.

7. Gay F et al.,: Sante 1994; Evaluation of the QBC system for the diagnosis of malaria.

8. Gaye O et al., Parasite 1999; A comparsion of thick smear, QBC, PCR and path falciparum malaria test strip in $P$. falciparium diagnosis.

9. Guthmann JP et al., Frans R, Soc. Trop. Med. Hyg. 2002. Validity, reliability and ease of use in the field of five rapid test for the diagnosis of $P$. falciparum malaria in Uganda.

10. Humar A, et al., 1997: Parasight falciparium test compared with the polymerase chain reaction and microscopy for the diagnosis of Plasmodium falciparum malaria in travellers. Am. J. Trop. Med. Hyg 56: 47 -48 .

11. Hunt. Cooke, A:et al., Comparison of a parasite lactate dehydrogenase - based ICT antigen detection assay (optiMAL) with microscopy for the detection of malaria parasites in human samples. Ann. J. Trop. Med. Hyg., 60: 20 -23.

12. Jelinek T, 2001. Evaluation of a dipstick test for the rapid diagnosis of imported malaria among patients presenting within the network. Trop Net Europe. Scand J. Infect Dis, 33: 752-754,

13. John's et al., 1998. Evaluation of optiMAL, a dipstick test for the diagnosis of malaria. Ann. Trop. Med. Parasitol., 92: 621 -622.

14. Srinivasan B. V et al., 2003. Comparison between conventional and QBG methods for diagnosis of malaria. Indian J. Pathol Microbiol.,

15. Lee MA et al., 1999. A comparison of antigen dipstick assays with polymerase chain reaction (PCR) technique and blood film examination in the rapid diagnosis of malaria. Ann, Acad. Med.,

16. Makler, M. J., C. J. Palmer, A. L. Ager 1992. A review of practical techniques for the diagnosis of malaria. Ann. Trop. Med. Parasitol., 92: 419-433.

17. Mason DP et al., 2002, A comparison of two rapid field immunochromatogenic tests to expert microscopy in the diagnosis of malaria. Acta Trop.

18. Mills CD et al., 1999 Evaluation of a rapid and inexpensive dipstick assay for the diagnosis of Plasmodium falciparum malaria. Bull World Health Organ,

19. Moody A et al., Performance of the optimal malaria antigen capture dipstick for malaria diagnosis and treatment monitoring at the hospital for tropical diseases, London. British J. Haematol 2000; 109: 891-894.

20. Nandwani S, Mathur M, Rawat S. Evaluation of the polymerase chain reaction analysis for diagnosis of falciparum malaria in Delhi, India. ISMM., 2005; 23; 176-178.

21. Oloo AJ et al., 1994: Evaluation of QBC method to detect malaria infections in field surveys. East Afr. Med. J.

22. Palmer C. L., et al., Evaluation of the optimal test for rapid diagnosis of Plasmodium vivax and Plasmodium 
falciparum malaria. J. Clin. Microbial 1998; 38: 203-2006.

23. Palmer CJ. 2003; Multicentre study of evaluate the optimal test for rapid diagnosis of malaria in US Hospitals. $J$. Clin. Microbial.

24. Park K, Text book of preventive and social medicine, $18^{\text {th }}$ edition, Jabalpur m/s Banarasidas Bhanot, 1997; Pp. 188201.

25. Pinto MJ et al., 1999. Rapid diagnosis of falciparum malaria by detection of Plasmodium falciparum HRP - 2 antigens. J. Assoc. Physician India.

26. Pinto MJW et al., Rapid diagnosis of falciparum malaria by detection of Plasmodium falciparum HRP- 2 Ag, JAPI 1999; 47(11): 1076-1078.

27. Sharma VP, Valecha N, Diagnosis of Malaria - Fam Med India, 1997; 1: 115.

28. Singh N, Valecha N, Sharma V. P., Malaria diagnosis by field workers using an immunochromatographic test. Trans R. Soc. Trop. Hyg. 1997; 91: 396397.

29. Tarimo DS, 2001. Malaria diagnosis and treatment under the stratergy of the integrated management of childhood illness relevance of lab support from the rapid immunochromatographic tests of
ICT Malaria $P$. falciparum and Plasmodium vivax and optiMAL. Ann. Trop Med parasitol,

30. Thepsamarn P, Prayoolawongsa N, Puksupa P, Puttoom P, Wongchai S, et al., -the ICT Malaria at the Thia Myanmar border. South East Trop med Public Health 1997; 28: 723-6.

31. Triasophon w, Raj Kulchai P, et al., A highly sensitive, rapid and simple polymerase chain reaction -based method to detect human malaria $(P$. falciparum and vivax) in blood samples. Am. J. Trop. Med. Hyg. 1993; 87: 6478.

32. Wang X et al., Bull World Health Organization 1996. Field evaluation of the $\mathrm{QBC}$ technique for rapid diagnosis of Vivax malaria.

33. WHO (1986). The Clinical Management of Acute Malaria. SEARO, SEA. Sr. NO. 9. New Delhi.

34. World Health Organization basic malaria microscopy Geneva; 1991 part IP. 17-68.

35. World Health Organization, 1999, New perspectives, Malaria diagnosis report of a joint WHO/USAID informal consultation, October 25 - 27, 1999 Geneva WHO/MAL/2000/1091.

\section{How to cite this article:}

Vaisakhi, K.S., Sujatha Kolla and Achut Rao. 2017. Comparative Study of Conventional Staining Techniques, Quantitative Buffy Coat, Immunochromatography Methods and Molecular Methods (Gene Amplification) for Diagnosis of Malaria. Int.J.Curr.Microbiol.App.Sci. 6(8): 395-409. doi: https://doi.org/10.20546/ijcmas.2017.608.053 